\section{The status, problems and development trend of China's industrial hemp}

\author{
Guangwen $\mathrm{Wu}^{\star}$, liguo Zhang, Yuyan Fang, Nan Zheng, \\ Ming Zhang, Xixia Song, Hongmei Yuan, Lili Cheng and Si \\ Chen
}

The Institute of Industrial Crops, Heilongjiang Academy of Agricultural Sciences, Harbin 150086, China

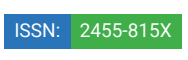

DOI: https://dx.doi.org/10.17352/ijasft
Received: 08 December, 2020

Accepted: 28 December, 2020 Published: 30 December, 2020

*Corresponding author: Guangwen Wu, The Institute of Industrial Crops, Heilongjiang Academy of Agricultural Sciences, Harbin 150086, China,

E-mail:wuguangwenflax@163.com

Keywords: Industrial hemp; Current situation; Problem; Trend

https://www.peertechz.com

\title{
Abstract
}

This article reviews the historical evolution, current status, existing problems and development trend of China's industrial hemp industry. The paper plays a role in promoting the healthy and sustainable development of China's industrial hemp industry.

Industrial hemp(Cannabis sativa.l) is a traditional crop in our country,it contains Tetrahydrocannabinol (THC) of $0.3 \%$ or less,grown in most provinces,has a wide range of uses and utilization value. It is a multipurpose crop that could be grown for its fiber,seed, oil, food, and medicinal properties.The whole plant can replace wood for papermaking and construction materials. seeds for making food and feed,oil for chemical raw materials and fuel ,Chinese medicinal materials, etc, and byproducts such as hemp hurds have been fully utilized abroad. The added value of its derivative products has increased significantly with the extension of the industrial chain,Hemp replenishes the soil and has been proven to remediate contaminated soils ,The hemp grown for fiber is tall, and its roots grow deep into the soil about $45-90 \mathrm{~cm}$. This enables the plant root to penetrate deep and increase the efficiency of removing widespread contamination as compared to other plants with a shallow root system, back in 1986 hemp was planted to help decontaminate the soil around the site where the Chernobyl Nuclear Disaster occurred [1-3]. Generally, it is considered as a crop that could be grown without any pesticides [4] for certain varieties [5]. Hemp has the potential to suppress weeds efficiently and can fit well in a crop rotation [6]. Additionally, some residues of hemp can be used as botanical insecticides, miticides, or repellants within programs of pest management in organic farming [7].

\section{China's industrial hemp planting is relatively concentra- ted}

The largest growing area is in Heilongjiang Province, According to statistics from the China Agricultural Statistical Yearbook and the United Nations Food and Agriculture Organization, China is the country with the largest industrial hemp cultivation area, accounting for about half of the world, mainly in Heilongjiang, Anhui, Henan, Shandong, Shanxi and Yunnan provinces. The industrial hemp cultivation reached a peak in the early 1980 s, with the planting area reaching 133,333 ha. In the 1990s, affected by the policy, the growing area was reduced to about 24,000 ha, and in 2005 decreased to about 10,000 ha. With the strong popularity of industrial hemp fiber products at home and abroad, domestic industrial hemp planting has begun to recover. In 2015, the total planting area nationwide increased to 27,500 ha (including 12,000 ha for seeds). In 2016, reached more than 40,000 ha [8].

From a national perspective, Heilongjiang Province is the largest industrial hemp planting area, with a planting area of about 20,000 ha during 2018-2019, the seed-use industrial hemp production areas are mainly distributed in Shanxi, Gansu, Inner Mongolia, Guangxi and Yunnan. The total area is about $6,600-13,300$ ha, the planting area in Yunnan is about 6,600 ha, which is mainly used for Cannabidiol (CBD) extraction. 
In recent years new hemp varieties with very good quality and less $0.3 \%$ THC content were released ,for example,fiber cartivars -Long dama 3,Qingma1,seed cultivars-Jin ma 4, Jin ma 5, medical varieties-Long dama 5,Yunma 7 ect Table 1.

Table 1: Hemp growing area distribution in China.

\begin{tabular}{|c|c|c|}
\hline Province & Hemp type(fiber,seed) & Planting area (ha) \\
\hline Heilongjiang & Fiber and seed & 20000 \\
\hline Jilin & Fiber & 2000 \\
\hline Inner Monggol Autonomous Region & Seed & 7000 \\
\hline Shanxi & Seed p & 14000 \\
\hline Shandong & Fiber & 200 \\
\hline Anhui & Fiber & 300 \\
\hline Yunnan & Medical & 6600 \\
\hline Guangxi & Seed & 3000 \\
\hline Gansu & Fiber & 2000 \\
\hline
\end{tabular}

The development of domestic industrial hemp industry is diversified

First is the steady development of the fiber-based hemp industry. In China, industrial hemp is mainly used as textile raw materials, and the annual processing capacity of textile is 30,000 tons. With the improvement of people's living standards, the requirements for the quantity, grade and quality of textiles are getting higher and higher. Hemp products of famous brands such as ZARA and MUJI are well accepted by the market. The second is that the seed-based industrial hemp industry is relatively small. China's seed-use hemp is mainly distributed in Shanxi, Inner Mongolia, and other places. Inner Mongolia has a relatively larger area for seed-use hemp, mainly for the cultivation of large-grain edible seed-use , with a yield of 1,500-2,250kg per hectare and about 22,500 yuan income, edible hemp seeds all over the country basically come from this area.

Shanxi mainly processes hemp oil and produces edible protein. Third, the medicinal hemp industry is in the ascendant. The development and application of extract CBD will surely occupy the commanding heights of the industrial chain. In the short term, due to the fact that domestic policies have not been liberalized, CBD will be mainly exported. From the longterm trend of industrial development, the layout of medicinal industrial hemp needs to focus on the development and utilization of CBD in the fields of medicine, health products, food, cosmetics and additives, and the market potential is great. Data shows that at the end of 2017, the market scale of China's CBD industry was only 448 million yuan, and it is expected that will increase to 1.8 billion yuan by 2024 . With the deep mining of CBD medicinal value, its market scale will continue to expand. At present, only a few factories in Yunnan are processing and extracting, there are few mass production enterprises, extraction technology is not yet mature, cost is relatively high.

\section{Existing problems}

The main problems for fiber: One is short of fine varieties of industrial hemp and the low hemp yield. The fiber rate of existing varieties is generally around $18 \%$, which is more than $5 \%$ lower than that of foreign varieties. The yield of retted straw per hectare is about 6 tons, which is much lower than that in west countries. This results in low efficiency for growers, low enthusiasm for planting. Second, lack of supporting high-yield cultivation techniques, planting and processing standards.The third is the lack of fiber processing capacity and the lack of coordination between planting and processing. In Heilongjiang Province, where fiber hemp accounts for more than $80 \%$ of the domestic share. So far, there is only one enterprise above designated scale in industrial hemp fiber processing, which can process 4000 tons of long fiber per year, digests 6,600 ha of industrial hemp. The tow is still difficult to be used, which seriously restricts the increase of planting . Fourth, the mechanization of key links of industrial hemp has not been solved. The problems of bundling, turning, and flower and leaf harvesting have plagued the production, which has seriously affected the large-scale production and cost reduction, resulting in the failure to release the advantage of large-scale planting.

Main problems existing in edible and medicinal industrial hemp: First, there is a serious shortage or low level of edible and medicinal varieties. At present, specific medicinal varieties are in a state of lack. Local varieties are often used in production, and there is a risk of out-of-control drug sources. Second, the content of CBD is low and the production cost is high. The medicinal materials currently used in domestic production are all less than $0.7 \%$, with high extraction costs and weak market competitiveness. The third is the lack of necessary policy support for the edible and medicinal hemp industry, making the cultivation of edible and medicinal hemp and the production and processing of CBD at the edge of the law, causing growers and enterprises to worry about intervening in the edible and medicinal hemp industry [9].

\section{Development trend of China's industrial hemp industry}

Introduce industrial hemp management system and allow CBD extraction and processing: Under the premise of strengthening supervision, the production management rules of the hemp industry will be promulgated, the extraction and production of effective ingredients such as CBD will be permitted, and the qualified enterprises will be clearly given processing qualifications, the agricultural department is responsible for the identification of industrial hemp varieties ,guarantee the legal source of seeds $[10,11]$.

Cultivate projects, increase publicity, and promote precise investment promotion: Extensive investment in new materials, short fiber textiles, comprehensive utilization of hurds, extraction of medicinal ingredients, research and development of production of medicines and cosmetics, and strive to comprehensively develop and utilize hemp flowers, stems, leaves, roots, seeds, etc. Form an integrated industrial chain of production, processing and sales. 
Establish a standardized industrial hemp production system: Establishes an industrial hemp production standard system, formulates planting quality management procedures and other corresponding standards [12].

Encourage scientific and technological innovation: Strengthen investment in scientific research, and improve the research and development capabilities of terminal products. Carry out in-depth research on practical technologies such as plant protection, biological degumming, harvesting and processing machinery, primary processing technology, and extraction of medicinal ingredients, and expand the research and development of deep processing technologies for multipurpose products from hemp hurds and seeds $[13,14]$.

Vigorously promote the research and development of specific hemp turning: Bundling, flower harvesting machines and other equipments. Encourage scientific research institutions and enterprises to introduce and absorb advanced related machinery and equipment to meet the actual needs of industrial development.

Breed Cultivars with high fiber and CBD content to meet market demands: Popularize integrated cultivation technology booting fiber, seed and CBD yield resulting in farmer income increase . Hemp industry will keep stable and sustainable development in accordance with the industrial chain stretching deeply and machinization improving.

\section{Funding}

This work was supported by the National bast fiber research system of China (CARS-19-S6), National Natural Science Foundation of China (31701480), Heilongjiang Academy of Agricultural Sciences Foundation (2019KYJL016, 2020FJZX032), and Bast fiber research system of Heilongjiang province (YYM19STX-22).

\section{References}

1. Ivanova R, Angelova V, Delibaltova V, Ivanov K (2003) Accumulation of heavy metals in fifibre crops flflax, cotton and hemp. J Environ Protect Ecol 4: 31-38. Link: https://bit.ly/3pOZqFR

2. Citterio S, Santagostino A, Fumagalli P, Prato N, Ranalli P, et al. (2003) Heavy metal tolerance and accumulation of $\mathrm{Cd}, \mathrm{Cr}$ and $\mathrm{Ni}$ by Cannabis sativa L. Plant Soil 256: 243-252. Link: https://bit.ly/3hv78So

3. Gryndler M, Sudova R, Puschel D, Rydlova J, Janouskova M, et al. (2008) Cultivation of high-biomass crops on coal mine spoil banks: Can microbial inoculation compensate for high doses of organic matter? Bioresour Technol 99: 6391-6399. Link: https://bit.ly/3b8G1vt

4. Desanlis F, Cerruti N, Warner P (2013) Hemp agronomics and cultivation. In Hemp: Industrial Production and Uses; Bouloc P, Allegret S, Arnaud L, Eds. CAB International: Wallingford, UK; Boston, MA, USA 98-124.

5. Struik PC, Amaducci S, Bullard MJ, Stutterheim NC, Venturi G, et al. (2000) Agronomy of fifibre hemp (Cannabis sativa L.) in Europe. Ind Crop Prod 11: 107-118. Link: https://bit.ly/3rEqGbz
6. Van der Werf H (2019) Crop Physiology of Fibre Hemp (Cannabis sativa L).

7. Benelli G, Pavela R, Petrelli R, Cappellacci L, Santini G, et al. (2018) The essential oil from industrial hemp (Cannabis sativa L.) by-products as an effffective tool for insect pest management in organic crops. Ind Crop Prod 122: 308-315. Link: https://bit.ly/3oePOn2

8. China 2019 Hemp Annal Report February 27, 2020. Link: https://bit.ly/2LcYo7y

9. Xiu YL, Chaoran Y, Wen G (2020) Advances in studies on the chemical composition and species differences of hemp. Chinese Journal of Traditional Chinese Medicine 45: 3556-3564.

10. Jin-yin L (2019) International trend and controversy of legalization of marijuana. Chinese journal of drug abuse prevention and control 25: 130-138.

11. Yousef NA (2020) Current legal status of medical marijuana and cannabidiol in the United States. Epilepsy \& Behavior 112: 107452. Link: https://bit.ly/3rJHaz4

12. Hawley P, Gobbo M, Afghari N (2020) The impact of legalization of access to recreational Cannabis on Canadian medical users with Cancer. BMC Health Serv Res 20: 977. Link: https://bit.ly/37YSXC2

13. Guanghui D, Gang D, Yang Y, Feihu L (2017) Nutrition composition, health function and food development of hemp seed. Journal of yunnan university (natural science edition), 39: 712-718.

14. Qiuyue W, Fang L, Shumin L (2014) Advances in Modern Research on the Medicinal Value of Cannabis and Cannabis. Pharmacology and Clinic of traditional Chinese Medicine 36: 222-227.

\section{Discover a bigger Impact and Visibility of your article publication with}

Peertechz Publications

Highlights

* Signatory publisher of ORCID

* Signatory Publisher of DORA (San Francisco Declaration on Research Assessment)

* Articles archived in worlds' renowned service providers such as Portico, CNKI, AGRIS, TDNet, Base (Bielefeld University Library), CrossRef, Scilit, J-Gate etc.

* Journals indexed in ICMJE, SHERPA/ROMEO, Google Scholar etc.

* OAI-PMH (Open Archives Initiative Protocol for Metadata Harvesting)

* Dedicated Editorial Board for every journal

* Accurate and rapid peer-review process

- Increased citations of published articles through promotions

* Reduced timeline for article publication

Submit your articles and experience a new surge in publication services (https://www.peertechz.com/submission).

Copyright: ( ) 2020 Wu G, et al. This is an open-access article distributed under the terms of the Creative Commons Attribution License, which permits unrestricted use distribution, and reproduction in any medium, provided the original author and source are credited.

Citation: Wu G, Zhang I, Fang Y, Zheng N, Zhang M, et al. (2020) The status, problems and development trend of China's industrial hemp. J Agric Sc Food Technol 6(2): 237-239. DOI: https://dX.doi.org/10.17352/2455-815X.000080 